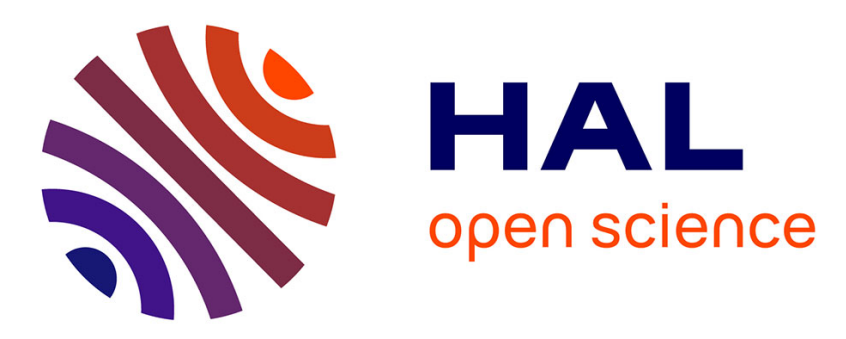

\title{
Experience modeling with graphs encoded knowledge for construction industry
}

Bernard Kamsu-Foguem, Fonbeyin Henry Abanda

\section{To cite this version:}

Bernard Kamsu-Foguem, Fonbeyin Henry Abanda. Experience modeling with graphs encoded knowledge for construction industry. Computers in Industry, 2015, vol. 70, pp. 79-88. 10.1016/j.compind.2015.02.004 . hal-01145918

\section{HAL Id: hal-01145918 https://hal.science/hal-01145918}

Submitted on 27 Apr 2015

HAL is a multi-disciplinary open access archive for the deposit and dissemination of scientific research documents, whether they are published or not. The documents may come from teaching and research institutions in France or abroad, or from public or private research centers.
L'archive ouverte pluridisciplinaire HAL, est destinée au dépôt et à la diffusion de documents scientifiques de niveau recherche, publiés ou non, émanant des établissements d'enseignement et de recherche français ou étrangers, des laboratoires publics ou privés. 


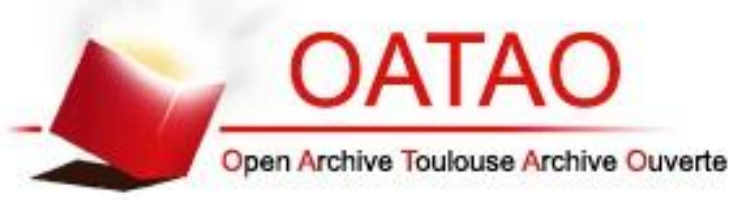

Open Archive Toulouse Archive Ouverte (OATAO)

OATAO is an open access repository that collects the work of Toulouse researchers and makes it freely available over the web where possible.

This is an author-deposited version published in: http://oatao.univ-toulouse.fr/ Eprints ID: 13767

Identification number: DOI: 10.1016/j.compind.2015.02.004

Official URL: http://dx.doi.org/10.1016/j.compind.2015.02.004

\section{To cite this version:}

Kamsu-Foguem, Bernard and Abanda, Fonbeyin Henry Experience modeling with graphs encoded knowledge for construction industry. (2015) Computers in Industry, vol. 70. pp. 79-88. ISSN 0166-3615

Any correspondence concerning this service should be sent to the repository administrator: staff-oatao@inp-toulouse.fr 


\title{
Experience modeling with graphs encoded knowledge for construction industry
}

\author{
Bernard Kamsu-Foguem ${ }^{\mathrm{a}, *}$, Fonbeyin Henry Abanda ${ }^{\mathrm{b}}$ \\ ${ }^{a}$ Laboratoire Génie de Production/ENIT-INPT - University of Toulouse, 47 Avenue d'Azereix, 65016 cedex, Tarbes, France \\ ${ }^{\mathrm{b}}$ Oxford Institute for Sustainable Development, Department of Real Estate and Construction, Faculty of Technology, Design and Environment, Oxford Brookes \\ University, Oxford, OX3 OBP, UK
}

Keywords:

AEC industry

Conceptual graphs

Domain ontology

Knowledge formalization

Visual reasoning

\begin{abstract}
A B S T R A C T
The Architecture, Engineering and Construction (AEC) industry is becoming increasingly knowledge intensive. Knowledge management has been hailed as an enabler for tapping this knowledge to improve efficiency in the AEC industry. In this study, the main concepts and benefits of knowledge management, relationships between knowledge management and continuous improvement have been examined. Furthermore, emphasis has been laid on knowledge management through experience feedback processes which constitute valuable assets for the AEC industry. This is done through the employment of ontologies and graph-based reasoning operations in eliciting and visualizing knowledge concepts in the AEC domain. The proposed approach which consists of two main aspects provides the opportunity to examine the conceptual and ontological knowledge models with associated reasoning. In the first, the concepts of knowledge management, their significance and application in the AEC field are discussed. The second deals with a methodological framework for the modeling and reasoning in the domain ontology. To facilitate automation, an ontology graph-based editor, Conceptual Graphs User Interface (CoGui) was used to model knowledge and encoded reasoning in the knowledge base. CoGui encodes knowledge as conceptual graphs and reasoning as graph operations that can be visualized in a logically precise way, based on domain ontologies. It emerged that CoGui could be very useful in acquiring information that can be used in collaboration with others to continuously improve information sharing and re-use. A French AEC company located in the Southwest region was employed as a case study in illustrating knowledge modeling through the experience feedback process. For each phase of experience feedback, actions that were implemented in the company are discussed.
\end{abstract}

\section{Introduction}

In the past, there has been no structured approach to learn from construction projects once they have been completed. Nowadays, the construction industry is adopting a sustainable strategy by using knowledge management concepts and techniques to improve the organization of knowledge from completed projects [9]. Knowledge can be seen as the means to extract and capture the available information which can be used to provide better and efficient ways of improving processes, producing and/or delivering construction products (e.g., buildings). For instance, experiences that relate lessons learned of how well a product could be produced, maintained, used and so forth [12]. Knowledge-based quality

\footnotetext{
* Corresponding author. Tel.: +33 6243023 37; fax: +33 562442708 . E-mail address: Bernard.Kamsu-Foguem@enit.fr (B. Kamsu-Foguem).
}

improvement involves experience feedback methodology that can be applied with three key methodological elements: (a) analysis with a set of tools; (b) a stepwise problem-solving method and (c) using common metrics [7]. With regards to the first, recommended tools include statistical techniques (e.g., design of experiments and regression analysis), and non-statistical tools (e.g., flow charts and fishbone diagrams, or both). A stepwise problem-solving offers a systematic analysis and impacts learning and knowledge creation and consists of the following steps: problem identification, diagnosis, solution generation and implementation. Furthermore, stepwise problem-solving technique provides models for problems visualization and systemic understanding of their main characteristics and the reasoning options available. The interaction between continuous improvements, experience feedback processes and stepwise problem-solving procedures leads to knowledge creation from structured learning processes [34]. Common metrics aid coordinate knowledge creation efforts by incorporating and aligning 
the problem-solving process aim at improving interaction and offer pragmatic solutions in work related situations. Despite the merits of the afore-mentioned experience feedback methodologies, common major challenges related to computing in civil and building engineering still exist. Tizani and Mawdesley [32] reported that (a) enhancing digital information modeling; (b) extending process modeling technologies; (c) improving decision-implication analysis, (d) integrating broader aspects of experience feedback processes are still quite common. Furthermore, in the field of civil engineering, studies about experience feedback tend to focus on structural aspects with little interest in preliminary stages of facilitating works. In France, experience feedback is more common in the field of industrial engineering than in AEC. The main reason is the automation of production systems in industrial engineering, compounded by the fact that industrial products often have similar characteristics.

It has been hailed that solutions for most knowledge management challenges lie in information and communication technologies (ICT). The increasing availability and quality of ICT; for example, the internet, underlying communication and emerging technologies are transforming the way people share knowledge and ideas. The ease of use and characteristics of these technologies have made them very popular in a very short period of time. However; compared to other industries, the AEC industry lags behind with regards to the successful implementation of ICT and in tapping the potential of the new and/or innovative technologies to improving productivity, achieving greater efficiency and higher quality [22]. Thus, knowledge of products, services and/or processes from past AEC projects are hardly fully exploited for use in other projects leading to information duplications, inconsistencies and inefficiencies in delivering such projects. This study aims to employ an ontology-driven approach to develop a knowledge management model for construction projects. The model will serve as a knowledge-based decision support system. To facilitate understanding, the paper is divided into four sections. Section 2 provides a background of the state-of-the-art about knowledge management applications in the construction industry. Section 3 presents an ontology-driven approach for knowledge modeling in the construction AEC industry. In Section 4, an illustrative case study is employed to depict the methodology and concepts of experience feedback. The discussion and analysis of major issues covered in this manuscript are discussed in Section 5 . The conclusion is presented in Section 6 by a way of summary of the key parts of the paper.

\section{State-of-the-art}

2.1. Generations of knowledge management applications in the AEC industry

Knowledge management is recognized as a key resource and a crucial enabler for continuous process improvement in construction projects. It has been widely acknowledged that one of the key sustainable advantages that a firm possesses comes from what it collectively knows, how efficiently it uses what it knows and how readily it acquires and uses new knowledge. Organizational knowledge could reduce the time spent on problem-solving and increases the quality of work. Recent developments in ICT have prompted organizations to utilize platforms such as corporate intranets and collaborative extranets for collaborative knowledge sharing. Companies are also implementing extranets to share information of experience feedback scenarios expressed for explicit knowledge capitalization and exploitation. In these situations, experience feedback is useful in terms of how well the organization works in many aspects, from learning knowledge from experience feedback information and using it in improving management strategies. The preceding statement underscores the difference between information and knowledge management. The right knowledge management adoption strategy should be put in place to develop and nurture core organizational competencies, and create intellectual capital by tapping or capturing experience feedback information. It has been argued that a true value creation culture can be found through the right combination of human networks, social, intangible and technology assets where issues such as change management, learning and trust must be blended successfully towards the vision of knowledge-enabled value creation. There has been an evolution of knowledge management over time [25]. The differences of the evolution are examined in Table 1.

In certain circumstances (e.g., the scarcity of specific data), it is not possible to move towards reliable analytical or statistical approaches [14,19] and experience feedback approach is then adopted as a more suitable alternative. However, Aamodt and Plaza [1] recommend that there must be a reasonable number of experienced cases that are sufficiently similar to be grouped together for potential application of the reasoning process over its underlying knowledge for use in new cases or projects. This underpins the concept of "experienced feedback".

\subsection{Knowledge management through experience feedback}

The usefulness of information structuring and knowledge capitalization from experience feedback in solving engineering problems have been examined in Gardoni et al. [10,11]. The experience feedback process consists of three essential steps (see Table 2): (i) the capitalization phase, (ii) the treatment phase, (iii) and the exploitation phase. In Table 2, the first two stages consist of capitalization and a synthesis of different stages of treatment in experience feedback. The third is about the exploitation phase of feedback for fault diagnosis systems, safety assessment (levels of protection), and forecasting changes in equipment over time.

In order to generate knowledge from experience feedback, a conceptual model [15] incorporating problem-solving to generate explicit knowledge from experiences is presented in Fig. 1.

Table 1

Three generations of knowledge management in the AEC industry.

\begin{tabular}{lll}
\hline Generations of KM criteria & Generation 1: knowledge sharing & $\begin{array}{l}\text { Generation 2: knowledge } \\
\text { conceptualization and nurturing }\end{array}$ \\
\hline Underpinning ICT & $\begin{array}{l}\text { Human interpretable knowledge } \\
\text { systems (knowledge embedded } \\
\text { in documents requiring human } \\
\text { interpretation) }\end{array}$ & $\begin{array}{l}\text { Semantic based systems(articulated } \\
\text { around the use of Building Information } \\
\text { Modeling or ontology) }\end{array}$ \\
$\begin{array}{l}\text { Information and communication } \\
\text { technology }\end{array}$ & $\begin{array}{l}\text { Systems managing knowledge as an } \\
\text { asset(leveraging the intellectual and } \\
\text { social capital of an organization) }\end{array}$ \\
$\begin{array}{l}\text { Lifecycle focus } \\
\text { Knowledge perspective }\end{array}$ & $\begin{array}{l}\text { Software application focus } \\
\text { Condition perspective emphasizing } \\
\text { access to information }\end{array}$ & $\begin{array}{l}\text { Discipline focus } \\
\text { Knowledge process perspective focusing } \\
\text { on knowing and acting }\end{array}$ \\
\hline
\end{tabular}


Table 2

Experience feedback process in line with continuous improvement [24].

\begin{tabular}{lll}
\hline $\begin{array}{l}\text { Phases of } \\
\text { experience } \\
\text { feedback }\end{array}$ & $\begin{array}{l}\text { Stages of } \\
\text { problem } \\
\text { solving }\end{array}$ & Definition of the stage \\
\hline $\begin{array}{l}\text { Capitalization } \\
\text { Treatment }\end{array}$ & $\begin{array}{l}\text { Problem } \\
\text { Reflection } \\
\text { Origins } \\
\text { Guide } \\
\text { Reaction }\end{array}$ & $\begin{array}{l}\text { Identification of problem } \\
\text { Analysis of problem } \\
\text { Investigation of causes } \\
\text { Search for possible solutions } \\
\text { Selection of the most } \\
\text { adequate solution }\end{array}$ \\
& $\begin{array}{l}\text { Execution } \\
\text { Monitoring }\end{array}$ & $\begin{array}{l}\text { Implementation of the solution } \\
\text { Monitoring of actions and } \\
\text { verification of the effectiveness } \\
\text { Generalization to prevent the } \\
\text { recurrence of similar problems }\end{array}$ \\
& Standardization &
\end{tabular}

In the AEC industry, the appropriate deployment of information structuring strategies with semantic knowledge can lead to efficient management of the key variables or factors that influence the built environment. For example, the use of semantic web and linked data to structure information for decision-making about energy, greenhouse gases, water or poor health have been reported in [2]. There are lessons to be learned from experiences in diverse contextual situations. An experienced actor could explore the knowledge in abundance covering different aspects of building construction to provide important work examples that is effective and instructive in construction activities. This approach involves the use of specialist information or knowledge from available records or sources where experts will exploit for use in their various applications such as diagnosis [6], risk analysis [21], safety assessment and security [31]. In fact, the conceptualization of the shared representations significantly influences the manner in which the collaborative work takes place, as evidenced by their contribution in the exchange of information and generated knowledge. Ontology provides a better way to explicitly specify concepts of any domain [13]. Therefore, in order to gain a better understanding of domain and to be able to make comprehensive analysis of the experience feedback processes in the AEC domain, an ontologydriven approach is adopted. Furthermore, ontologies provide means to formalize domain knowledge in a way that makes it accessible, shareable, reusable and machine processable.

\section{Ontology-driven approach for knowledge modeling in AEC}

In this section, an ontology-driven approach for knowledge modeling in AEC is proposed. This approach provides opportunities for sustained continuous improvement and re-use of knowledge in AEC industry. In software engineering the task of rendering information to an end-user through the implementation of any computer system often involves three separate layers: the presentation, the application or business logic and data (data management processes) layers (see Fig. 2). This is often called the hybrid system, client-server architecture or 3-tier architecture.

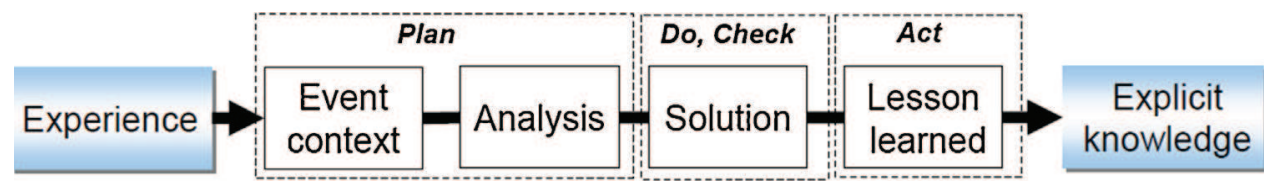

Fig. 1. Experience model incorporating problem-solving technique (Kamsu Foguem et al. [15]).

N-Tier Architecture

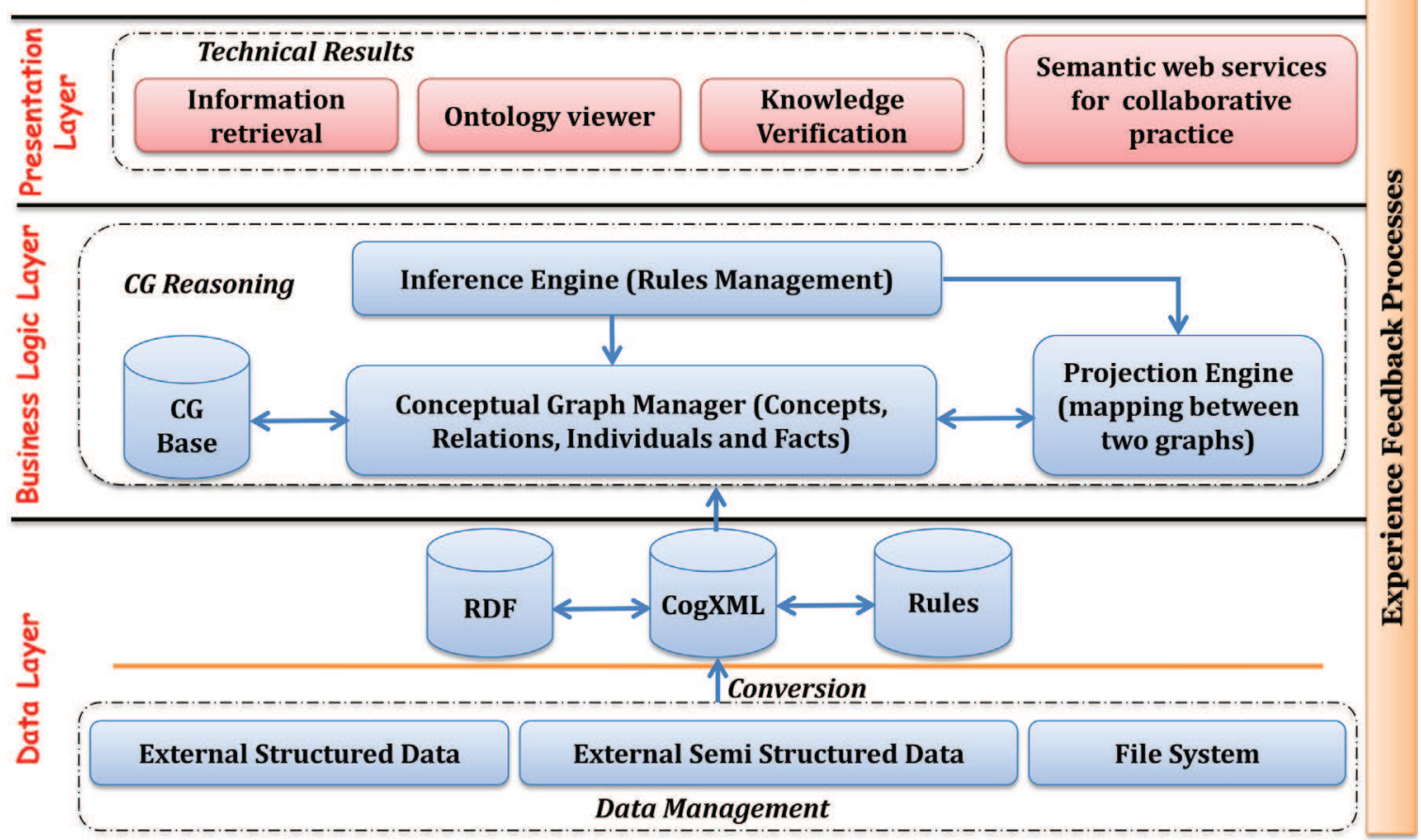

Fig. 2. N-tier architecture supporting the used framework. 
Access to the presentation layer is often through the use of a graphical user interface (GUI) or a web browser. As argued by [3], the implementation of the 3-tier model in its full generality and the invocation of access via the internet or web browser is called an Ntier model. The N-tier model has the following advantages: adaptability, encapsulation, re-use and quality.

The implementation will be performed according to each technology involved in a given layer. In order to demonstrate how each layer feeds the other, the data layer implementation will be conducted before the application layer. It is important to note that within the scope of this study, the focus will only be on the data and business logic layers. The development of a user-friendly interface (i.e. the presentation layer) is reserved as part of future study.

With regards to the data layer, the main technology in it is the CoGui graphical knowledge representation model which can store information about any domain of discourse [29]. The data captured in CoGui is from external documents and storage systems which could be non-structured, semi-structured or structured. Once edited into CoGui, the CoGui knowledge model can be converted into different file/data model formats (e.g., Resource Description Framework (RDF)) for other uses such as in application development. The model can also be enriched with conceptual graph rules and constraints to capture real life situations [17, 35-43]. The rules and constraints are based on Concepts Types, Relationship Types and Individuals. With regards to the business logic layer, its main purpose is to extract relevant parts from the CoGui experience feedback knowledge base, stored in the form of a CogXML file format. This data is obtained from the data layer. It contains the conceptual graphs base "CG base" that communicates with the "Conceptual Graph Manager". The "Projection Engine" is a reasoning engine based on the semantic mapping between conceptual graphs involving both adjacent concepts and relations. The constraint checking is a procedure for verification of the essential requirements and expectations in the CG base. The "Inference Engine" is a reasoning and deductive process applying rules (if their conditions are true) to the available facts in order to generate new conclusions. In fact, the rules are applied only when required conditions are in compliance with considered facts and/or available hypotheses. The crucial aspect of the architecture presented in Fig. 2 is the ontology development using CoGui. All what is required to be undertaken in the data and business logic layers can be undertaken within the CoGui environment. In the ensuing sections, the ontology development procedures using CoGui will be examined.

\subsection{Graph-based ontology development technique}

To develop the ontology, a graph-based technique has been used to represent knowledge about the domain of interest. This technique enables real-time changes to be made to find faster and clearer solutions for different applications [8]. For any knowledge representation, it is important to establish the requirements to be fulfilled by the application for which the knowledge model is being developed for. To this end, the following requirements have been set:

- A wider application field to allow the satisfaction of certain needs of expanding the ground in which knowledge can be shared. This constitutes the first big step for having a properly positioned experience feedback process in a continuous improvement environment.

- A formal conceptualization of a collaborative work system should be considered for purposes of shared representations in supporting the process of collective knowledge creation, evaluation and learning from experiences.
- A simple and clear procedure to manage and exploit the appropriate information. It is highly advisable to go for the less crowded and the most explicit way of data represention and visualization

- A feasible implementation of the solution to reality: This implies that the solution should bring more benefits than problems. It is known that the full exploitation requires a period of fine tuning in terms of use and operational application.

The AEC industry is noted for generating huge amount of information from construction projects. For this information to be effectively shared, a well-organized method is required to minimize ambiguity. Hence, the rationale for adopting an ontology approach to disambiguate inconsistencies and facilitate understanding and reasoning. As explained earlier, an ontology formally represents knowledge as a set of concepts within a domain, and the relationships between pairs of concepts. It can be used to model a domain and support reasoning about entities. From this perspective, ontology provides a viable and efficient technique of sharing experience feedback knowledge. As argued in [30], one of the best ways to employ ontology to capture the above requirements is to adopt conceptual graph representation. To this end, CoGui, a graphical and development ontology editor is used in modeling a real world application of experience feedback in the construction domain.

\subsection{Knowledge modelling with conceptual graphs}

Conceptual Graphs user interface $\left(\mathrm{CoGui}^{1}\right)$ is a free graph-based visual tool, developed in Java, for building conceptual graph knowledge bases represented in CogXML format, compatible with Cogitant [4]. CoGui makes it possible to create, edit and control the structure and content, of a knowledge base. The knowledge base can be serialized in the XML format called CogXML. Such a knowledge base is composed of an ontological knowledge, a factual knowledge represented by a set of conceptual graphs and procedural knowledge described by conceptual graph rules (see Fig. 3). The conceptual graph can be simple or nested for embedded descriptions of knowledge representation.

\subsubsection{Ontology representation}

According to [5], the basic components of an ontology is the vocabulary, which consists of:

- A hierarchy of concept types (also called concepts), which represents the kinds of entities in the application domain. These concepts could be defined to be disjoint or to have an intersection;

- A hierarchy of relation types (also called relations), which represents the kinds of relationships between entities, and may have any number of arguments;

- A set of individuals (or individual names) and graphs associated with individuals, which represent knowledge about these individuals;

- A set of conceptual graph rules takes the form of an implication between an antecedent (body) and a consequent (head). The intended meaning is read as: whenever the conditions specified in the antecedent holds, then the conditions in the consequent must also hold.

\subsubsection{Conceptual graphs formalism}

Conceptual graphs were introduced by Sowa as a diagrammatic system of logic with the purpose "to express meaning in a form

\footnotetext{
${ }^{1}$ http://www.lirmm.fr/cogui/
} 


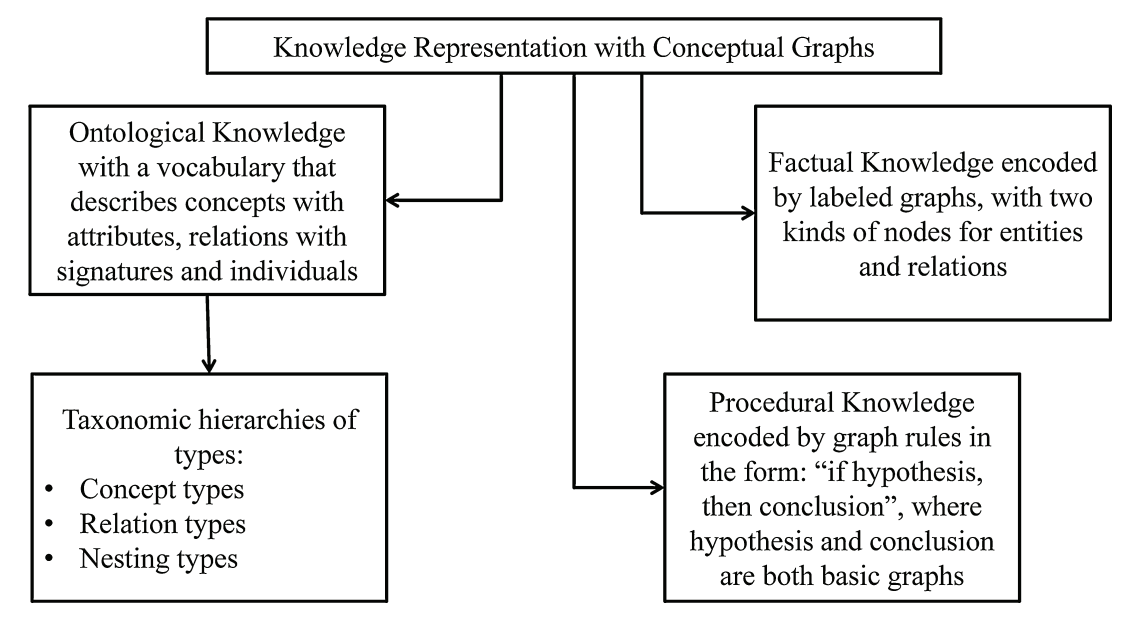

Fig. 3. A pictorial representation of the modeling components.

that is logically precise, human readable and computationally tractable" [28]. Conceptual graphs encode knowledge as graphs and thus can be visualized in a natural way [30]:

- The vocabulary, which can be seen as a basic ontology, is made of hierarchies of concepts and relations.

- All other kinds of knowledge are based on the representation of entities and their relationships. This representation is encoded by a labeled graph, with two kinds of nodes, respectively corresponding to entities and relations. Edges link an entity node to a relation node.

- A rule expresses implicit knowledge of the form: "if hypothesis, then conclusion", where the hypothesis and conclusion are both basic graphs. Using such a rule consists of adding the conclusion graph (to some fact) when the hypothesis graph is present. There is a one-to-one correspondence between some concept nodes of the hypothesis with concept nodes of the conclusion. Two nodes in correspondence refer to the same entity. These nodes are said to be connection nodes. The knowledge encoded in rules can be made explicit by applying the rules to specified facts.

Having discussed the graph-based ontology development process in Section 3, in Section 4, the steps will now be applied to a case study.

\section{An illustrative modeling case in the French context}

A French AEC company located in the southwest region has been used as a case study to illustrate knowledge modeling of the experience feedback process. This company is active in two sectors: public works and building. The main activities often undertaken by the company are public works (e.g., roads, railroads, bridges, water supply, sewage and electrical grid) and buildings (e.g., universities and hospitals). This study focused on facilitating works as defined by the UK New Rules of Measurement (NRM) [26]. The facilitating works were related to six tramway projects being constructed by company $\mathrm{X}$ (for data protection purposes, $\mathrm{X}$ is assumed to be the name of the company) in the Southeast region of France. Facilitating works include specialist works which normally need to be completed before any building works can commence (e.g., major demolition works, soil stabilization works and/or temporary diversion of mains drainage). The key challenges associated with construction of tramway platforms were the quality and safety needs, the regulatory constraints and minimum traffic disruptions. The rationale for choosing the UK NRM is because of its wellestablished structure and popularity of its use in other countries. It provides definitions for different work elements in a construction project than most standard measurement methods. By adopting the NRM standards, it is easier to map concepts elicited from feedback processes. In the adopted modeling approach, an individual (e.g., experience feedback manager) in the company responsible for experience feedback treatment undertook the following tasks discussed in the ensuing paragraphs.

Firstly, information from company's project are gathered or elicited. This can be achieved in two ways [33]. The experience feedback manager completes a record of information gathered from the treatment of experienced cases, and then conducts interviews with key actors of projects having potential interesting lessons that can be learned. Based on these, the feedback manager established records of collected information in order to generate useful knowledge. Secondly, the structured or semi-structured forms of experience feedback activities prepared by the feedback manager which can also be obtained and prepared by any actors through interviews are saved in a database. This is stored for purposes of knowledge reuse in AEC [20]. After completing this collection of information, it is analyzed to determine the type, richness and its usefulness. The identification of different types of information depends on the associated knowledge and also on their importance. Examples of categories include information gathered associated with onsite practical problems (e.g., lack of safety on site) and simple information that can be useful afterwards (e.g., use of a new material). With regards to the tramway projects, some actions were undertaken to elicit knowledge about experience feedback processes. The actions implemented are summarized in Table 3.

On the one hand, in the engineering phase of a construction of the tramway projects the capitalization concerns data collection from specific projects related to design phase (new materials, used efficiency coefficients, particular production mechanisms.). The treatment is about the different ways used to address the facilitating work challenges and the search for reasonable solutions. The exploitation defines the means within for information retrieval and the dissemination of the interesting results of lessons learnt. On the other hand, in the engineering phase of a construction project the capitalization is for the execution and coordination of the studies by the architectural and engineering team and for the actual works. The treatment concerns the actions undertaken in finding solutions to recurrent problems and more feasible alternatives. The exploitation of feedback is achieved through meetings with the aim of preventing problems, or to deliver solutions.

Upon collecting the information as described in Table 3, the following key ontological concepts elicited were developed and will be discussed in the ensuing sections. 
Experience feedback activities conducted in the case study.

\begin{tabular}{|c|c|c|}
\hline $\begin{array}{l}\text { Execution phases } \\
\text { of a construction } \\
\text { project. }\end{array}$ & $\begin{array}{l}\text { Type of experience } \\
\text { feedback }\end{array}$ & Activities conducted \\
\hline \multirow[t]{3}{*}{ Engineering } & Capitalization & $\begin{array}{l}\text { - Data collection from specific projects related to design phase (new materials, used efficiency coefficients, particular } \\
\text { production mechanisms.) } \\
\text { Interview with site workers, foremen, site supervisors and construction managers. }\end{array}$ \\
\hline & Treatment & $\begin{array}{l}\text { - The person is seeking alone some solutions to the problems during its working time. } \\
\text { Talks with others affected by the problem for collaborative problem solving. }\end{array}$ \\
\hline & Exploitation & $\begin{array}{l}\text { - Ascertained and recorded solution. } \\
\text { Solution transmitted (orally, by mail, by phone ...) to individuals involved in the study phase. }\end{array}$ \\
\hline \multirow[t]{9}{*}{ Construction } & Capitalization & - Collected data: \\
\hline & & $\begin{array}{l}\text { Passed from the foreman to site supervisors (security issues, problems on a machine, a material used, bad } \\
\text { equipment ...). }\end{array}$ \\
\hline & & Amendments made during quality/safety meetings. \\
\hline & & Execution and coordination of the studies by the architectural and engineering team and for the actual works. \\
\hline & Treatment & - The actors are trying to find solutions to recurrent problems \\
\hline & Exploitation & - Memorandum, diagrams, or any other practical documents. \\
\hline & & Safety Data Sheet. \\
\hline & & Meetings to prevent existing problems, or to deliver solutions. \\
\hline & & Quality/security manager of the considered area informed of the progress (by e-mail, phone ...). \\
\hline
\end{tabular}

\subsubsection{Concept types}

Based on the definition of the facilitating works [26], concepts or classes with their respective sub-concepts were abstracted and modeled in CoGui (see Fig. 4).

Based on Fig. 4, the first levels in the hierarchy are Toxic/ Hazardous/contaminated material treatment, Major demolition

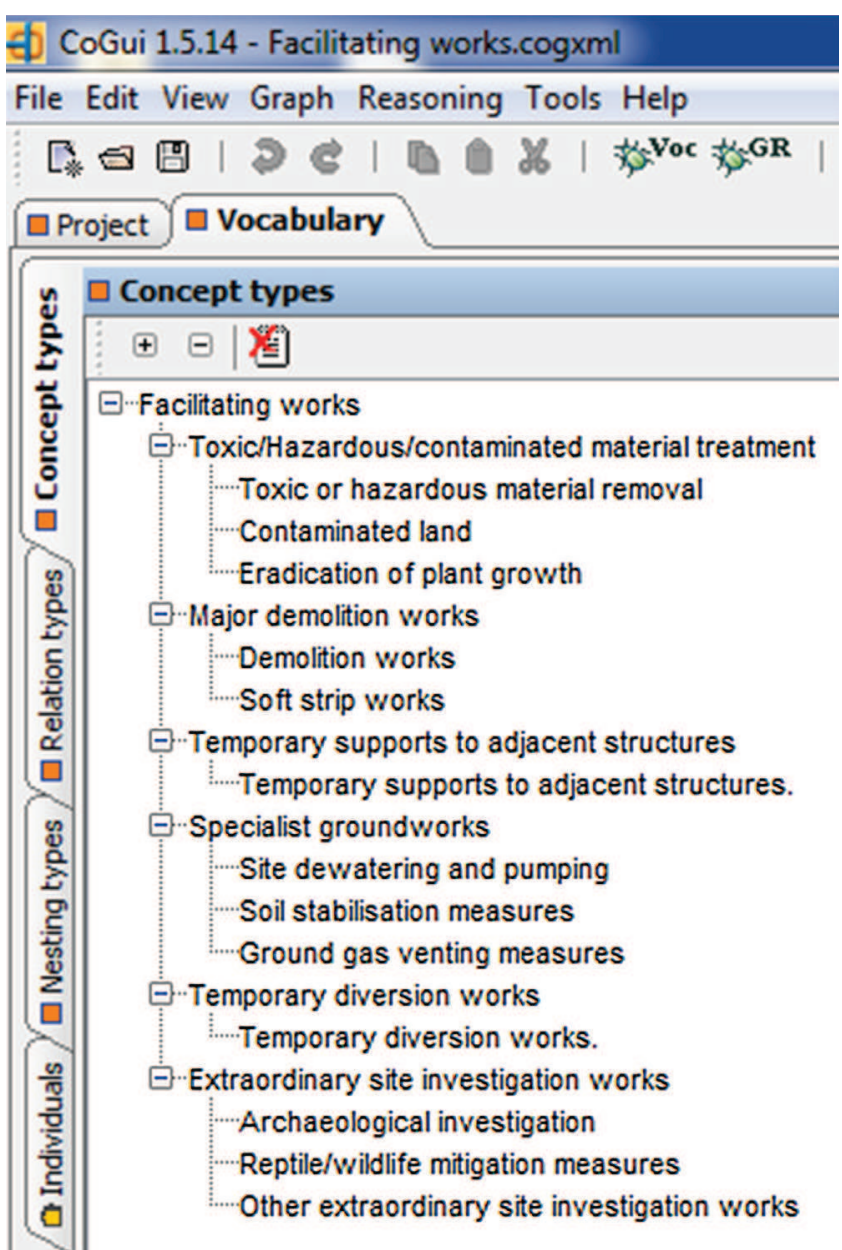

Fig. 4. Concept types of facilitating works. works, Temporary support to adjacent structures, Specialist groundworks, Temporary diversion works and Extra-ordinary site investigation works. These top level concepts also contain subconcepts. Some relations may be established between the concepts and used for the modeling of factual and procedural knowledge in conceptual graphs. This can facilitate automated reasoning in experience feedback processes.

\subsubsection{Relation types}

Fig. 5 depicts the relationships (Logical operators, Comparison operators, Usual relations and Temporal relations) between concepts, including their respective branches created. Logical operators (such as AND, NOT, OR and XOR) are used in combining two or more relational expressions into a single expression that evaluates to either true or false. Comparison operators (Equal, Less than and Greater than) can be used to compare two concepts with the logical true and false results. Usual relations (such as Agent, Attribute and Object) refer to the construction of sentences in terms of subject, verb and complement in the common language with active and passive components. Temporal relations (such as After, before and during) are used for the temporal descriptions of events.

\subsubsection{Facts and rule applications}

After creating the concept and relation types, the relevant constraints and rules are created to facilitate understanding, only rules related to four sub-elements of the third level will be examined. The elements are "Toxic or hazardous material removal", "Demolition works", "Soil stabilization measures" and "Archaeological investigation". Toxic or hazardous material removal is a concept describing the removal, employing special safety measures, of toxic or hazardous material prior to demolition or refurbishment works. Fig. 6 represents the modeling of an associated rule in the conceptual graph formalism. The rule in Fig. 6 means, if a certain project has components (object) with a toxicity value greater than a given threshold level then the object should be detoxified.

Logical expression: $\exists x \exists y \exists z$ (Project $(x) \wedge$ Toxicity $(y) \wedge$ Upper Threshold $(z) \wedge$ Attribute $(x, y) \wedge$ Superior $(y, z) \rightarrow \exists u$ (Project $(x) \wedge$ Detoxification $(u) \wedge \operatorname{Object}(u, x))$

Soil stabilization measures is a concept describing the stabilization or improvement of soil bearing capacity or slip resistance of existing ground to facilitate construction by injecting or otherwise 


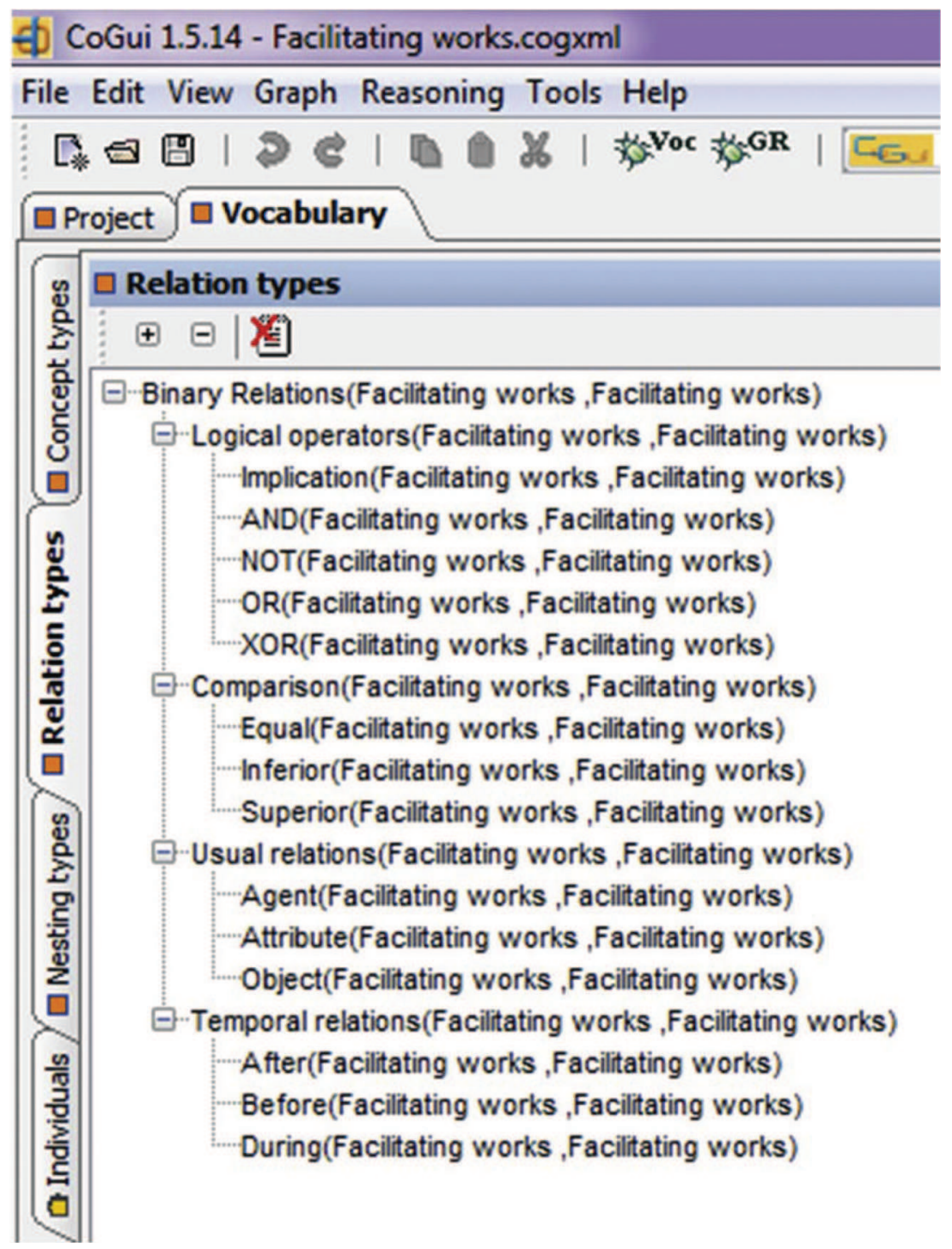

Fig. 5. Relation types.

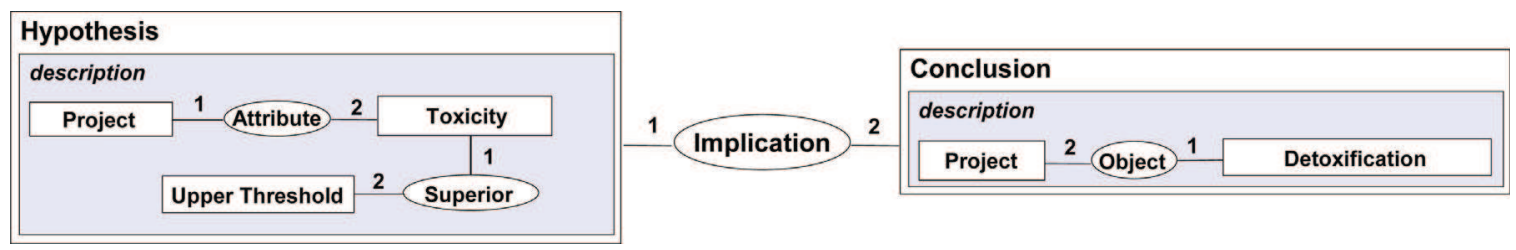

Fig. 6. A rule modeling a situation for the detoxification.

introducing stabilising materials, by power vibration, by soil nailing or by ground anchors. Fig. 7 represents the modeling of an associated rule in the conceptual graph formalism. The rule in Fig. 7 means that if the value of the soil physical stability where the project is being undertaken is less than a given threshold value, a soil stabilization measure should be performed which consists of improving the soil bearing capacity and/or slip resistance of project.

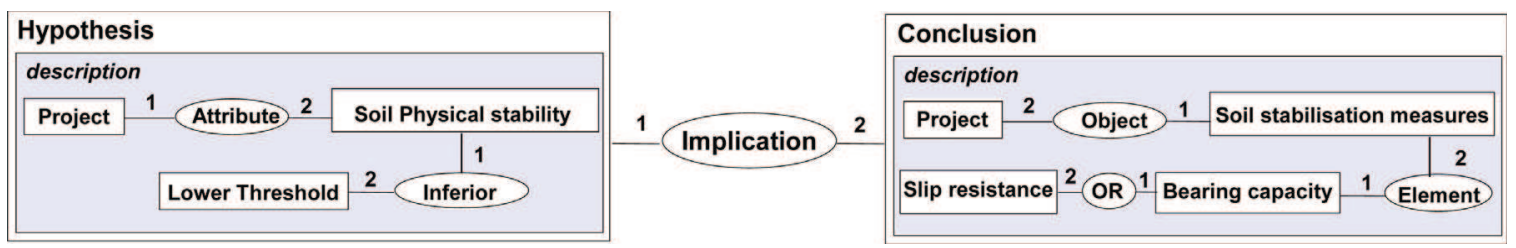

Fig. 7. A rule modeling a situation for the soil stabilization measures. 


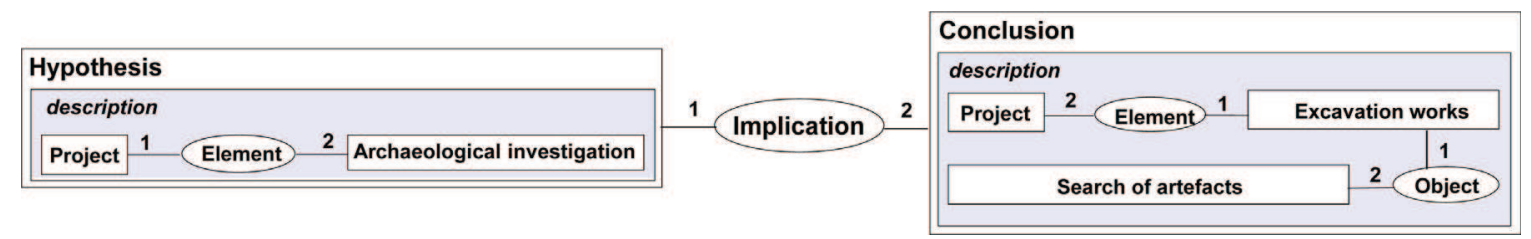

Fig. 8. A rule modeling a situation for the archaeological investigation.

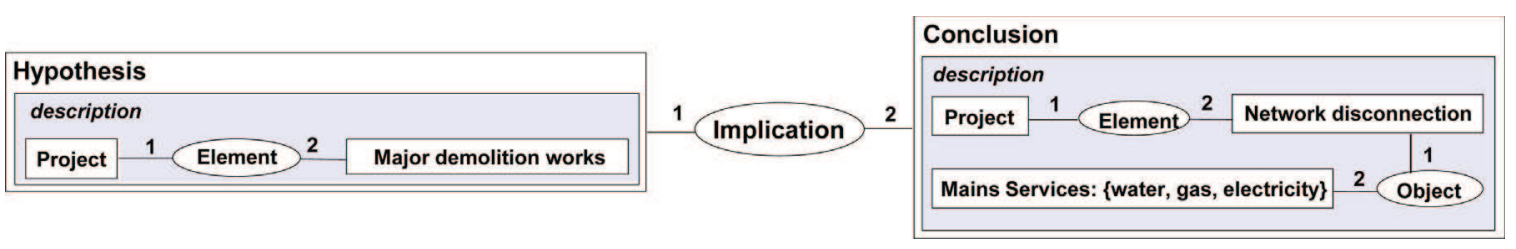

Fig. 9. A rule modeling a situation for the major demolition works.

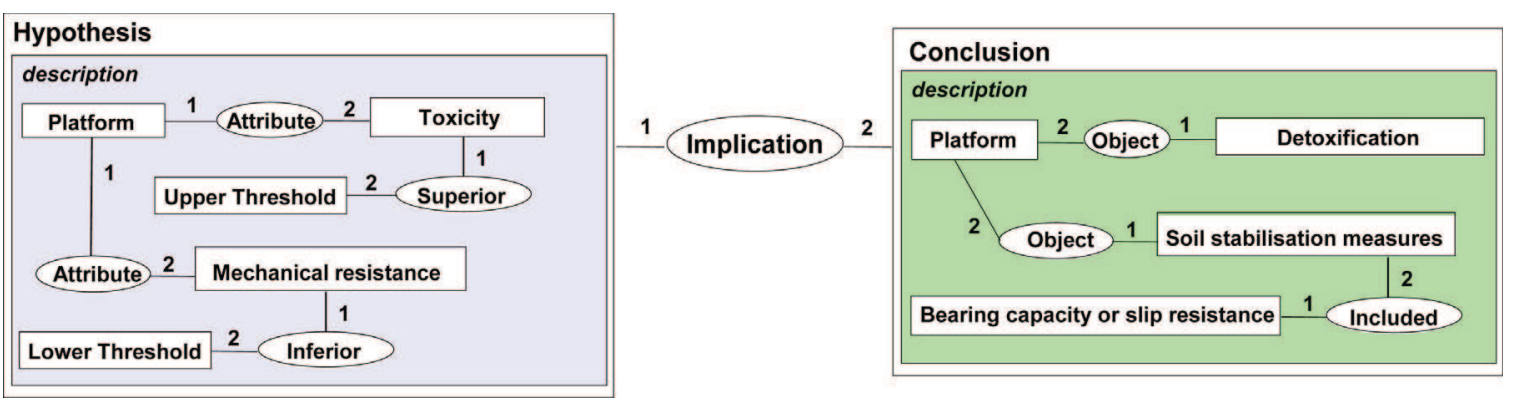

Fig. 10. Selection of a fact for the application of the relevant rules.

Logical expression: $\exists x \exists y \exists z$ (Project $(x) \wedge$ Soil Physical stability $(y) \wedge$ Lower Threshold $(z) \wedge$ Attribute $(x, y) \wedge$ Inferior $(y, z)) \rightarrow \exists u \exists v$ $\exists w$ (Project $(x) \wedge$ Soil stabilization measures $(u) \wedge$ Bearing capacity $(v) \wedge$ Slip resistance $(w) \wedge \operatorname{Object}(x, u) \wedge$ Element $(u, v) \wedge O R(v, w))$.

Physical archaeological investigation works are site based excavation works in search of artefacts and the like carried out by the main contractor under the guidance and instruction of an archaeologist. Fig. 8 represents the modeling of an associated rule in the conceptual graph formalism. The rule in Fig. 8 means that if a project is located on an archaeological grounds, then excavations works and the search of archaeological artefacts should be undertaken.

Logical expression:: $\exists x \exists y$ (Project $(x) \wedge$ Archaeological investigation $(y) \wedge$ Element $(x, y) \rightarrow \exists u \exists v$ (Project $(x) \wedge$ Excavation works $(u) \wedge$ Search of artefacts $(v) \wedge$ Element $(x, u) \wedge \operatorname{Object}(u, v))$

Demolition works concern the taking down to ground level and removing complete buildings/structures or parts of buildings/ structures, including services, fittings and finishes. Fig. 9 represents the modeling of an associated rule in the conceptual graph formalism. The rule in Fig. 9 means that if major demolition works are to be undertaken on a project's site, all services' networks should be disconnected.

Logical expression: $\exists x \exists y$ (Project $(x) \wedge$ Major demolition works $(y) \wedge$ Element $(x, y) \rightarrow \exists u$ (Project $(x) \wedge$ Network disconnection $(u) \wedge$ Element $(u, v) \wedge$ Mains Services $(\{$ water, gas, electricity\}) $\wedge \operatorname{Object}(u,\{$ water, gas, electricity $\}))$

Based on facts presented in Figs. 6 and 7, an illustration of the general principle regarding the application of any rule will be examined. This is presented in Fig. 10, where the selection of a fact activates an applicable rule. The application of the two previous facts and rules concerns the facilitating works for the construction of a tramway management platform in the outskirts of Toulouse.
The platform provides services supporting the coordination and the monitoring of tramway vehicles serving the community including the remote parts.

The rules 6-9 are implemented in CoGui. After the fact and rules are selected, the simulation is launched. The simulation results will serve as a basis to highlight issues that need to be addressed.

As an example, the right of Fig. 10 is the output of the execution of the facts on the left of the same rule. It is important to note that the visibility of the simulated results in CoGui was very poor, and could not be read when the screen was snapped. Consequently, the output on the right of Fig. 10 is coloured green just to indicate that it is an actual output from CoGui.

\section{Discussions}

In the case study examined, a key observation that can be made about the procedure is the fact that challenges associated with the facilitating works can be modeled using conceptual graphs and enriched with rules to facilitate reasoning. By developing an ontology knowledge base that includes feedback processes, it is possible to re-use in future in solving a large majority of problematic situations. An example of a practical problem solved is the decision to stabilize the soil if the soil bearing capacity is lower than a given threshold value (Fig. 7). Reasoning in the knowledge based is facilitated by both the Projection and Inference engines in CoGui. In addition to strengths of these engines, CoGui conceptual graph-based structure makes it easy to organize and sort information that can be used in corporations for continuous improvement in construction projects. In France, the application of experience feedback in improving organizations' efficiency is more common in the field of industrial engineering than in AEC sector. The main reason is because of the automation of production systems in industrial engineering compounded by the fact that 
industrial products often have similar characteristics. Thus, it is not uncommon to find experience feedback applications in industrial repairs and maintenance management ([16], [18]; Potes [23]). While experience feedback process can easily be applied in industrial production/engineering, because most of its tasks/ products are often repetitive and standardized, its application in AEC is very challenging. This is because each AEC project is often unique in nature. With regards to renovation/refurbishment projects, the challenge is even enormous as each existing building structure has different characteristics and different levels of defects requiring different appraisal strategy or surveying techniques before recommendation for repairs and maintenance. That notwithstanding, and given the knowledge intensive nature of AEC projects, developing an ontology knowledge base about experience feedback processes provides an opportunity to structure knowledge that can be re-used in solving problems on different projects.

\section{Conclusion and related works}

The rationale for this study stemmed from the fact that knowledge is an important asset of an organization including AEC companies; many AEC companies are yet to tap on the full potential of knowledge from already executed projects. Companies are aware of situations in their organizations in which costly errors have been made because knowledge was not available when and where it was needed and because employees did not know how to interpret or use the information available to them. These situations are mainly due to the project-based nature of the construction industry and the fact that knowledge is embedded in social relations. Nevertheless, for those big companies who might be carrying out international projects, strategies to mobilize knowledge is critically important. In construction organizations, time is often associated with the need to deliver projects according to schedule. Many construction organizations believe that their organizational structure requires heavy procedures and long processing times to exploit domain knowledge. Employees may be willing to share knowledge, but the pressure to deliver projects under tight schedule and budget makes them have very low appetite to take on additional responsibility for knowledge management activities. In this manuscript, it was revealed that useful knowledge on AEC projects and businesses or organizations can be helpful in resolving persistent, complex and workload problems. Eliciting experience feedback knowledge is core to re-using existing knowledge that can improve organizational efficiency in product (e.g., buildings) delivery. This is enshrined in the methodology for knowledge capitalization from semi-structured information and unstructured information in industrial engineering domain $[10,11]$. Graphical conceptual modeling is very powerful as it allows lessons learned to be captured and represented textually and graphically, facilitating visualization. This improves communication to users who may be interested in consuming knowledge about feedback from previous projects [27]. In this study, we adopted the N-tier model to develop the ontology knowledge base containing experience feedback knowledge from tramway projects constructed in the Southeast region of France. The focused of the paper was on the data and business logic layers. As part of future study, the development of a user-friendly interface will be investigated. It is also important to note that, although the ontology developed is based on tramway projects in Southeast France, the concepts and rules are generic and can be re-used on any other tramway projects in any country. Such a move should only focus on facilitating works.

\section{Acknowledgement}

This work has been undertaken as part of the collaborative research funded through two organisations whose goals are to encourage interdisciplinary research work. Firstly, the authors were awarded a grant by the Ecole Nationale d'Ingénieurs de Tarbes through the "Projet Soutien á la Mobilité Internationale (SMI) 2014" programme. Secondly, the authors were awarded another grant by the Oxford Brookes University through Central Research Funding Scheme. The authors gratefully acknowledge the financial support received.

\section{References}

[1] A. Aamodt, E. Plaza, Case-based reasoning: foundational issues, methodological variations, and system approaches, Artificial Intelligence Communications 7 (1994) 39-59.

[2] F.H. Abanda, J.H.M. Tah, R. Keivani, Trends in built environment semantic Web applications: where are we today? Expert Systems with Applications 40 (2013) 5563-5577.

[3] G. Alonso, F. Casati, H. Kuno, V. Machiraju, Web Services Concepts, Architectures and Applications, Springer Verlag, Berlin, Germany, 2003.

[4] J.F. Baget, M. Chein, M. Croitoru, A. Gutierrez, M. Leclère, M.L. Mugnier, Logical, graph based knowledge representation with CoGui, in: Actes de l'atelier GAOC (Graphes et Appariement d'Objets Complexes en conjonction avec EGC'10), 2010, 15-25.

[5] M. Chein, M. Mugnier, Graph-based Knowledge Representation: Computational Foundations of Conceptual Graphs, Springer, London, UK, 2009.

[6] C.-Y. Chang, M.-D. Tsai, Knowledge-based navigation system for building health diagnosis, Advanced Engineering Informatics 27 (2013) 246-260.

[7] A.S. Choo, K.W. Linderman, R.G. Schroeder, Method and context perspectives on learning and knowledge creation in quality management, Journal of Operations and Management 25 (2007) 918-931.

[8] R. Dieng, O. Corby, Conceptual graphs for semantic web applications, in: F. Dau, M.L. Mugnier, G. Stumme (Eds.), Proceedings of the 13th International Conference on Conceptual Structures (ICCS'2005), Springer-Verlag, Kassel, Germany, 2005, pp. 19-50 (July 17-23, 2005, LNAI 3596).

[9] N. Forcada, A. Fuertes, M. Gangolells, M. Casals, M. Macarulla, Knowledge management perceptions in construction and design companies, Automation in Construction 29 (2013) 83-91.

[10] M. Gardoni, M. Spadoni, F. Vernadat, Harnessing non-structured information and knowledge and know-how capitalisation in integrated engineering: case study at Aerospatiale Matra, Concurrent Engineering 8 (4) (2000) 281-296.

[11] M. Gardoni, C. Frank, F. Vernadat, Knowledge capitalisation based on textual and graphical semi-structured and non-structured information: case study in an industrial research centre at EADS, Computers in Industry 56 (1) (2005) 55-69.

[12] J. Goulding, W. Nadim, P. Petridis, A Alshawi, Construction industry offsite production: a virtual reality interactive training environment prototype, Advanced Engineering Informatics 26 (2012) 103-116.

[13] T.R. Gruber, A translation approach to portable ontology specifications? Knowledge Acquisition 5 (2) (1993) 199-220.

[14] J. Juhásová, R. Sofronie, R. Bairrão, Stone masonry in historical buildings-Ways to increase their resistance and durability, Engineering Structures 30 (8) (2008) 2194-2205

[15] B. Kamsu-Foguem, T. Coudert, C. Béler, L. Geneste, Knowledge formalization in experience feedback processes: an ontology-based approach, Computers in Industry 59 (2008) 694-710.

[16] B. Kamsu-Foguem, Knowledge-based support in non-destructive testing for health monitoring of aircraft structures, Advanced Engineering Informatics 26 (2012) 859-869.

[17] B. Kamsu-Foguem, G. Diallo, C. Foguem, Conceptual graph-based knowledge representation for supporting reasoning in African traditional medicine, Engineering Applications of Artificial Intelligence 26 (2013) 1348-1365.

[18] B. Kamsu-Foguem, D. Noyes, Graph-based reasoning in collaborative knowledge management for industrial maintenance, Computers in Industry 64 (2013) 998-1013.

[19] K. Kovler, N. Roussel, Properties of fresh and hardened concrete, Cement and Concrete Research 41 (2011) 775-792.

[20] K.Y. Lin, S.H. Hsieh, H.P. Tserng, K.W. Chou, H.T. Lin, C.P. Huang, K.F. Tzeng, Enabling the creation of domain-specific reference collections to support textbased information retrieval experiments in the architecture, engineering and construction industries, Advanced Engineering Informatics 22 (2008) 350-361.

[21] H.-L. Liu, Y.-L. Tsai, A fuzzy risk assessment approach for occupational hazards in the construction industry, Safety Science 50 (2012) 1067-1078.

[22] A. Moum, C. Koch, T.I. Haugen, What did you learn from practice today? Exploring experiences from a Danish R\&D effort in digital construction, Advanced Engineering Informatics 23 (2009) 229-242.

[23] P.A.P. Ruiz, B. Kamsu-Foguem, D. Noyes, Knowledge reuse integrating the collaboration from experts in industrial maintenance management, KnowledgeBased Systems 50 (2013) 171-186.

[24] H. Rakoto, P. Clermont, L. Geneste, Elaboration and exploitation of lessons learned, 93, IFIP-The International Federation for Information Processing, Montréal, Québec, Canada, 2002, pp. 297-300.

[25] Y. Rezgui, C.J. Hopfe, C. Vorakulpipat, Generations of knowledge management in the architecture, engineering and construction industry: an evolutionary perspective, Advanced Engineering Informatics 24 (2010) 219-228. 
[26] RICS (2012) NRM1. Order of cost estimating and cost planning for capital building works. UK, The Royal Institution of Chartered Surveyors.

[27] J.D. Silvestre, J. de Brito, Ceramic tiling in building façades: inspection and pathological characterization using an expert system, Construction and Building Materials 25 (2011) 1560-1571.

[28] J.F. Sowa, Conceptual graphs for a database interface, IBM Journal of Research and Development 20 (1976) 336-375.

[29] J.F. Sowa, Conceptual Structures: Information Processing in Mind and Machine, Addison-Wesley, Reading, MA, 1984.

[30] J.F. Sowa, Knowledge Representation: Logical, Philosophical, and Computational Foundations, Brooks/Cole Publishing Co, Pacific Grove, CA, 2000.

[31] D. Theodossopoulos, B. Sinha, A review of analytical methods in the current design processes and assessment of performance of masonry structures, Construction and Building Materials 41 (2013) 990-1001.

[32] W. Tizani, M.J. Mawdesley, Advances and challenges in computing in civil and building engineering, Advanced Engineering Informatics 25 (2011) 569-572.

[33] E. Wenger, R. McDermott, W.M. Snyder, Cultivating Communities of Practice, Harvard Business School Press, Boston, 2002.

[34] X. Zhang, X. Mao, S.M. AbouRizk, Developing a knowledge management system for improved value engineering practices in the construction industry, Automation in Construction 18 (2009) 777-789.

[35] B. Kamsu-Foguem, Ontological view in telemedicine, European Research in Telemedicine / La Recherche Européenne en Télémédecine 3 (2) (2014) 67-76.

[36] B. Kamsu-Foguem, G. Tchuenté-Foguem, C. Foguem, Verifying a medical protoco with temporal graphs: The case of a nosocomial disease, Journal of Critical Care 29 (4) (2014) 690.e1-690.e9.

[37] B. Kamsu-Foguem, G. Tchuenté-Foguem, C. Foguem, Conceptual graph operations for formal visual reasoning in the medical domain, IRBM - Innovation and Research in BioMedical Engineering 35 (5) (2014) 262-270.

[38] B. Kamsu-Foguem, D. Noyes, Graph-based reasoning in collaborative knowledge management for industrial maintenance, Computers in Industry 64 (8) (2013) 998-1013.

[39] B. Kamsu-Foguem, G. Tchuenté-Foguem, C. Foguem, Using conceptual graphs for clinical guidelines representation and knowledge visualization, Information Systems Frontiers 16 (4) (2014) 571-589.

[40] B. Kamsu-Foguem, A. Flammang, Knowledge description for the suitability requirements of different geographical regions for growing wine, Land Use Policy 38 (2014) 719-731.

[41] B. Kamsu-Foguem, V. Chapurlat, Requirements modelling and formal analysis using graph operations, International Journal of Production Research 44 (17) (2006) 3451-3470

[42] P.A.P. Ruiz, B. Kamsu-Foguem, D. Noyes, Knowledge reuse integrating the collaboration from experts in industrial maintenance management, KnowledgeBased Systems 50 (2013) 171-186.

[43] P.A.P. Ruiz, B. Kamsu-Foguem, B. Grabot, Generating knowledge in maintenance from Experience Feedback, Knowledge-Based Systems 68 (2014) 4-20.

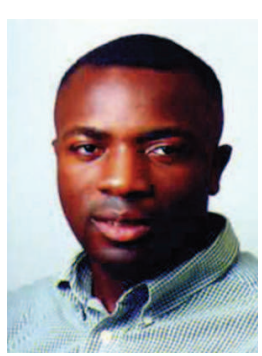

Dr. Bernard Kamsu-Foguem is currently a tenured Associate Professor at the National Engineering Schoo of Tarbes (ENIT) of National Polytechnic Institute of Toulouse (INPT) and undertakes research in the Production Engineering Laboratory (LGP) of ENIT-INPT, a research entity (EA1905) of the University of Toulouse. He is a visiting scholar in some renowned universities: United Kingdom (e.g. Oxford Brookes University, Oxford), Finland (e.g. Aalto University, Helsinki University of Technology, VTT Technical Research Centre of Tampere, University of Oulu, Åboakademi of Turku University). He is a member of
International Editorial Reviewer Board of Artificial Intelligence Research and a reviewer for a large number of international scientific journals such as KnowledgeBased Systems, Engineering Applications of Artificial Intelligence, International Journal of Production Research, Journal of Intelligent Manufacturing, Computer Methods and Programs in Biomedicine, Computers in Biology and Medicine, Interacting with Computers, Sensors and Knowledge Management Research \& Practice. He has a Master's in Operational Research, Combinatorics and Optimization (2000) from National Polytechnic Institute of Grenoble, and a PhD in Computer Science and Automation (2004) from the University of Montpellier 2. Based on his research activities and outputs including 30 peer-reviewed publications amongst others, he achieved the "accreditation to supervise research" status (abbreviated HDR) from INPT in 2013. This status allows Dr.Kamsu-Foguem to be able to independently supervise PhD students. His recent research interest focuses on methodologies and modelling related to knowledge representation and reasoning methods of Artificial Intelligence that support knowledge-intensive activities with interdisciplinary perspectives in different applications (e.g. industrial engineering, construction industry and health care). He is a member of the group: e-Health of InterOP-VLab (International Virtual Laboratory for Enterprise Interoperability). The aim of InterOP-VLab is to link together in a network researchers and research institutions and industry representatives, engaged in developing approaches and integrative solutions to connect heterogeneous industrial systems, public administrations or organizations. InterOP-VLab was founded in 2007 and is the continuation of the INTEROP Network of Excellence (Interoperability research for networked enterprise applications and software), a research initiative of the European Union founded early 2000s, which developed the Model Driven Interoperability Framework.

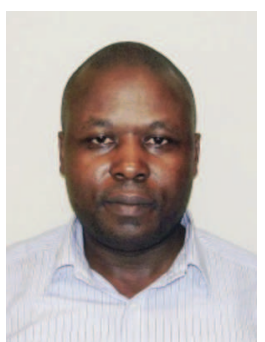

Dr. Fonbeyin Henry Abanda is a Senior Lecturer in the Department of Real Estate \& Construction in Oxford Brookes University, UK. Henry is a visiting scholar at the Ecole Nationale d'Ingénieurs de Tarbes, an engineering institution in Institut National Polytechnique de Toulouse, France. He is a Chartered Engineer with the UK Institution of Engineering and Technology. He has achieved the Renewable Energy Expert status from the European Energy Centre based in Scotland. He has a BSc (Hons) and Dipl.-Ing. in Mathematics/Physics and Civil Engineering respectively. After obtaining his degree in Civil Engineering in 2003, Henry worked as a Project Engineer on projects funded by the governments of Cameroon and Japan. Henry obtained his PhD from the Faculty of Technology, Design \& Environment at Oxford Brookes University in the UK in 2011. His PhD investigated the extent to which Semantic Web technologies can be used in managing sustainable building technology knowledge for use in different building projects. As a main contribution, the study culminated in the development of a photovoltaic decision support system called PhotoVoltaic Technology Ontology System (PV-TONS). The system provides a means of designing and selecting photovoltaic systems and components for use in building projects. Henry is currently extending his PhD study to include other sustainable building technologies such as wind turbines, geothermal and combined heat and power systems. During and after his PhD study, Henry has contributed to writing research proposals for securing research grants/funding for a number of research councils and organisations including the Engineering \& Physical Sciences Research Council, the International Labour Organisation, Oxford Brookes Reinvention Centre, and Persimmon Homes-UK. In addition, Henry has worked as a Chapter Science Assistant at the Intergovernmental Panel on Climate Change where he contributed to the writing of the Fifth Assessment Report on climate change mitigation recently published in 2014. 